\title{
A systematic review of the individual determinants of research evidence use in allied health
}

This article was published in the following Dove Press journal:

Journal of Multidisciplinary Healthcare

25 July $201 \mathrm{I}$

Number of times this article has been viewed

\section{Lizarondo \\ K Grimmer-Somers \\ S Kumar}

International Centre for Allied Health Evidence, University of South Australia, Adelaide, South Australia, Australia
Correspondence: Lucylynn Lizarondo International Centre for Allied Health Evidence, C7-62 Centenary Building, City East Campus, University of South Australia, North Terrace, Adelaide SA 500I, Australia

Tel +6I 883022099

Fax +6I 883022766

Email lucylynn.lizarondo@unisa.edu.au
Background: The use of evidence-based practice (EBP) is often not reflected in allied health (AH) practitioners' day-to-day practice (the research-practice gap). Research suggests that considerable differences between and within $\mathrm{AH}$ disciplines exist, which require different approaches in order to influence practice behavior. It is therefore important to develop a better understanding of what influences individual AH practitioners' adoption of evidence into daily practice.

Objective: This systematic review aims to examine the individual characteristics of $\mathrm{AH}$ practitioners which determine their uptake of evidence into practice.

Methods: Studies which examined individual factors or variables that influence research evidence use by any AH practitioner were included in the review. The methodological quality of the included papers was assessed using the Quality Assessment and Validity Tool for Cross-sectional Studies. A narrative summary of the findings was presented.

Results: Six studies were included and the methodological quality scores indicated that two were weak and the remainder had moderate-weak quality. The review demonstrated that factors such as educational degree or academic qualification, involvement in research or EBP-related activities, and practitioners' perceptions, attitudes and beliefs about research and EBP are significant predictors of self-reported research evidence use in $\mathrm{AH}$. The effect of other factors such as professional characteristics, clinical setting/work environment, information-seeking behavior and sociodemographic variables are less clear. Whether there is an interaction effect between evidence-uptake factors has not been tested.

Conclusion: Improving the research knowledge of clinicians and overcoming negative attitudes toward EBP have the potential to move AH practitioners towards regularly utilizing evidence in practice. Allied health practitioners may benefit from participation in regular educational opportunities such as case studies or journal clubs which can put them at the same level of thinking and awareness of research evidence. Future research should aim to review organizational and contextual factors and explore their interaction with individual determinants of research evidence use.

Keywords: evidence-based practice, research use, individual determinants, allied health, predictors

\section{Introduction}

Evidence-based practice (EBP) involves the integration of three key components: knowledge arising from one's clinical expertise/clinical reasoning, patient's preferences and research evidence. ${ }^{1}$ Allied health $(\mathrm{AH})$ practitioners are increasingly expected to use EBP as a basis for making clinical decisions. ${ }^{2}$ There is little information on what prompts practitioners to make evidence-based decisions for clinical practice, or the ways in which 
they subsequently implement these decisions. Thus, because of the importance of ensuring that health care is evidence-based, this is an area of increasing research endeavor.

The literature suggests that $\mathrm{AH}$ practitioners in general have positive attitudes toward EBP, and believe their practice should be evidence-based. ${ }^{3-6}$ However, despite their recognition of its importance and value, their use of EBP is often not reflected in an individual AH practitioner's dayto-day practice. ${ }^{4,7}$ This is called the research-practice gap. For many AH practitioners, regularly utilizing evidence in practice may be an ongoing challenge. For example, in a survey conducted on 1755 rehabilitation practitioners in Canada (ie, physiotherapists, occupational therapists, speech pathologists), their use of family-related interventions for post-stroke clients was low, despite evidence of its effectiveness on stroke outcomes. ${ }^{9}$ Thus, unless treatment is based on current evidence, patients may be receiving suboptimal or even ineffective treatment.

The literature outlines differences between and within $\mathrm{AH}$ disciplines in terms of practitioners' knowledge and skills relevant to EBP. ${ }^{2,10}$ Their learning needs appear to vary according to their disciplines and prior research experience. ${ }^{3,11}$ There are also considerable differences in terms of practitioners' access to evidence resources and the support they receive from their professional association, and their employer/training institution.,10 This highlights that there is no "one-size-fits-all" strategy to promote research evidence uptake into practice that is likely to be effective for all $\mathrm{AH}$ practitioners or for all organizations in which AH practitioners work. Thus it appears to be important to recognize differences within and between $\mathrm{AH}$ practitioners and disciplines, which may require different approaches in order to influence evidence-into-practice behaviors.

Applying research findings to clinical decisions is not a simple process and is often difficult to achieve. There are two elements related to the successful implementation and uptake of evidence in $\mathrm{AH}$ : the practical component and the knowledge component. ${ }^{3,4,6}$ The practical component refers to the time and resources to search for, access, analyze, and interpret the evidence as well as the organizational support to implement evidence into practice. The knowledge component, on the other hand, relates to health practitioners' understanding of research concepts (eg, designs, methods, analysis, interpretation) which will allow them to become proficient readers of research. To bridge the gap between research and practice, these practical and knowledge barriers need to be understood and addressed.

There is scant research evidence from intervention studies which evaluate the effectiveness of strategies which aim to promote EBP uptake by $\mathrm{AH}$ practitioners. Those studies which are available demonstrate either modest or no effects. ${ }^{7,12,13}$ One of many reasons for this could be the failure to systematically account for factors that influence individual $\mathrm{AH}$ practitioner's use of research evidence in day-to-day practices. It is therefore necessary to develop a better understanding of what factors influence individual $\mathrm{AH}$ practitioners' adoption of evidence into daily practice, so that these can be addressed by targeted training.

The aim of this review is to examine literature which describes individual characteristics of $\mathrm{AH}$ practitioners which could influence their uptake of research evidence. For the purpose of this review, AH practitioners include physiotherapists, occupational therapists, speech pathologists, dieticians, social workers, psychologists, podiatrists, ambulance paramedics, music therapists, art therapists, exercise physiologists, and intensive care paramedics. ${ }^{14}$ An understanding of individual determinants of research evidence use is necessary to design targeted interventions to address the research-practice gap.

\section{Methods}

Studies that examined the influence of individual factors on the uptake of research evidence by any $\mathrm{AH}$ practitioner were considered. Uptake of research evidence refers to any of the following:

- the extent to which the key steps involved in EBP (formulating a clinical question, searching for the most appropriate evidence to address the question, critically appraising the retrieved evidence, incorporating the evidence into a strategy for action, and evaluating the effects of any decisions and action taken) are integrated into day-to-day practice

- research- or information-seeking behavior

- use of research-based information

The review was limited to correlational studies because this type of research examines the relationships between variables. Only articles published in the English language were included, with no restriction on publication date. Studies were included if they measured both an independent (ie, one or more potential individual determinants of AH practitioner's uptake of research evidence) and a dependent variable (ie, any measure of research evidence use), evaluated the influence of the independent variable on the dependent variable, and reported this relationship in terms of strength of association. ${ }^{15}$

\section{Search strategy}

Relevant articles were identified using a wide range of keywords grouped into three categories. Concept one 
represented keywords in the category of "allied health", concept two represented "evidence-based practice", and concept three represented keywords in the category of "determinants." These three concepts were combined in the electronic search in order to capture the most number of relevant articles.

Concept one: "allied health" or "allied health practitioner" or "allied health personnel" or physiotherap* or "physical therap*" or "occupational therap*" or "speech therap*" or "speech patholog*" or diet* or nutrition* or "social work*" or psycholog* or podiatr* or "ambulance paramedic" or "music therap*" or "art therap*" or "exercise physiolog*" or "ambulance officer" or "intensive care paramedic".

Concept two: "getting knowledge into practice" or "getting research into practice" or "translating research into practice" or "evidence implementation" or "knowledge exchange" or "knowledge transfer" or "knowledge use" or "diffusion of innovation" or "evidence-based practice" or "research utilization" or "research use" or "research transfer" or "research uptake" or "research translation" or "knowledge translation" or "evidence translation" or "evidence uptake".

Concept three: predict* or determinant or "individual characteristic".

The following electronic databases were searched:

- Academic search premier

- Biomed Central Gateway

- CINAHL

- Cochrane Library

- Current Contents Connect

- ERIC

- EMBASE

- PsycARTICLES

- Psych Info

- TRIP Database

- Web of Science

- HighWire Press

- Informit e-library

- Journal citation reports

- Meditext

- MEDLINE

- PubMed

- PubMed central

- Science citation index expanded

- Science Direct

- Scopus

The reference lists of retrieved papers were scrutinized for additional studies that were not indexed in any of the electronic databases.

\section{Selection of studies for inclusion}

The titles and abstracts of articles identified from the search strategy were independently reviewed by two reviewers (LL and SK) to determine eligibility for inclusion. Full texts of potentially relevant papers were retrieved for a more detailed examination. The decision to include or exclude studies, based on the set criteria, was made independently by the same authors. Disagreements regarding adherence to inclusion criteria were resolved by discussion.

\section{Critical appraisal}

The methodological quality of the included papers was assessed independently by two authors (LL and SK) using the Estabrooks' Quality Assessment and Validity Tool for Crosssectional Studies. ${ }^{15}$ The tool consists of twelve criteria which examine sampling, measurement, and statistical analysis. The quality score of each included study was calculated by dividing the total number of points obtained by the total number of possible points, yielding a score between 0 and 1 for each study. The studies were then classified as weak $(<0.50)$, moderate-weak (0.51-0.65), moderate-strong (0.66-0.79), or strong (0.80-0.10). ${ }^{15}$ Differences in opinion were resolved by discussion. All relevant articles were included in the review irrespective of their methodological quality.

\section{Data extraction and analysis}

The first author (LL) extracted a range of information from each included study, comprising setting, participants, individual determinants or predictors of research evidence use (independent variables), outcome measures used to evaluate evidence uptake (dependent variable), and findings from each study. Extracted data were double-checked by another author (KGS) for accuracy. A quantitative synthesis of findings was not possible due to the heterogeneity of variables (individual determinants) and outcomes examined by individual studies. Thus, findings were synthesized in a qualitative manner to construct a narrative summary.

\section{Results}

The search strategy identified 654 publications, which were reviewed by the authors (LL, KGS, SK) for duplicates. A total of 468 studies were screened for possible inclusion in the review and only 36 were considered to be potentially relevant and were retrieved for closer examination. After scrutiny, 30 articles were further excluded as they did not meet the inclusion criteria, leaving six studies for the systematic review. Figure 1 illustrates the process involved in the selection of studies for review. 


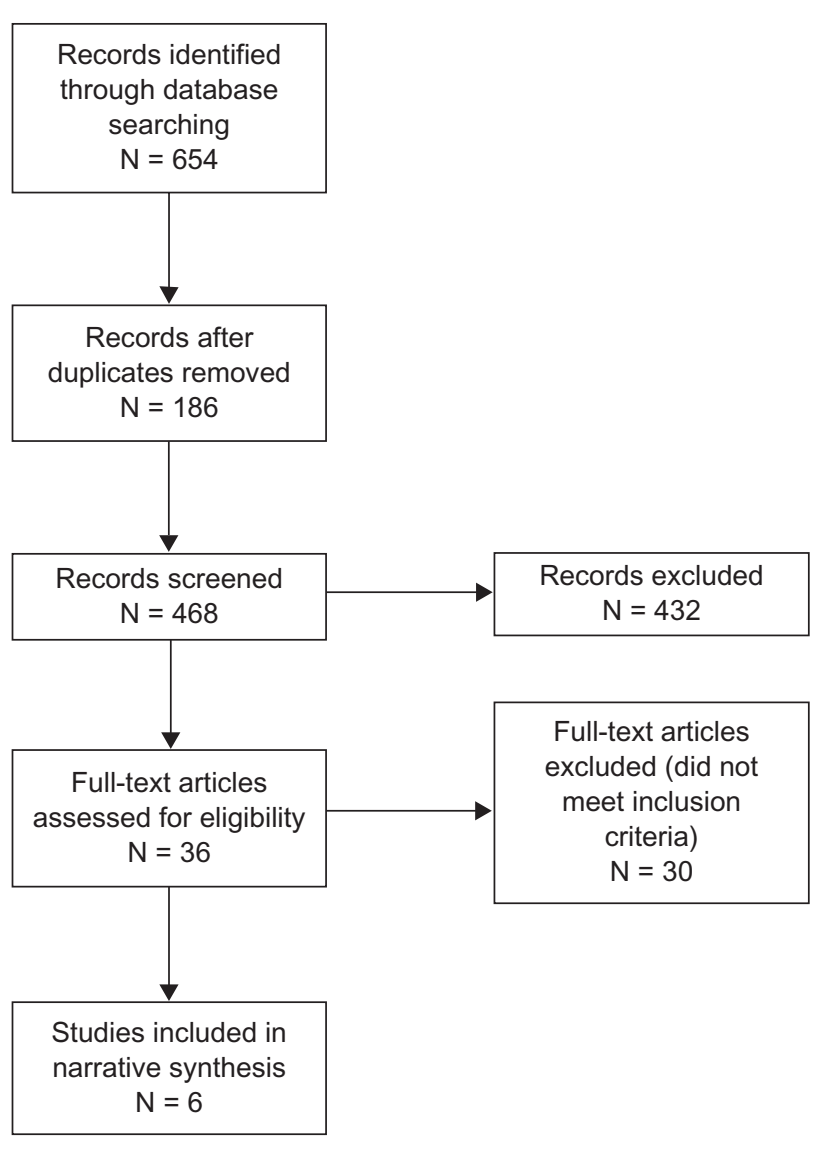

Figure I Flowchart of article selection process.

\section{Overview of included studies}

All six studies that met the inclusion criteria were survey designs, and used self-reported questionnaires to gather data on research evidence uptake by $\mathrm{AH}$ practitioners. Of these, three examined predictor variables in physiotherapy ${ }^{16-18}$ and there was one each for occupational therapy, ${ }^{19}$ social work and psychology, ${ }^{20}$ and nutrition/dietetics. ${ }^{21}$ Three of the studies $(50 \%)$ were undertaken in the US, one in Canada, another in Australia and one study had participants from Australia, the UK, and Taiwan.

\section{Methodological quality of included studies}

Quality rating scores were either 0.43 or 0.64 , indicating that two studies were of weak methodological quality, and four had moderate-weak strength. Table 1 summarizes the methodological quality scores obtained by each of the included studies.

All studies drew their sample from more than one site, and achieved a response rate of more than 50\%. More than half of the papers $(67 \%)$ reported use of random sampling and $50 \%$ appeared to have adequate sample size. In all studies, measurement of the dependent variable (research evidence use) was undertaken using self-reported questionnaires. These questionnaires had acceptable reliability in half of the studies and adequate levels of validity in most of the papers (67\%). Appropriate statistical tests were used in all studies, with the majority ( $83 \%$ ) reporting $P$-values, however only two $(33 \%)$ presented confidence intervals. Not one of the studies described missing data or how this was managed.

\section{Individual determinants of research evidence use in $\mathrm{AH}$}

In all studies, research uptake outcomes were measured using self-reported questionnaires that examined information-seeking behavior, propensity to adopt EBP, and use of EBP in clinical practice. Table 2 summarizes the individual determinants investigated by each of the included studies, including the outcome measures used.

The individual determinants extracted from relevant studies were categorized into seven subgroupings of information: sociodemographic factors, education, beliefs and attitudes, involvement in research or EBP-related activities, professional characteristics/experiences, clinical setting, and information seeking. Table 3 reports the predictor variables examined by individual studies and highlights those which were found to

Table I Summary of methodological quality score

\begin{tabular}{|c|c|c|c|c|c|c|c|c|c|c|c|c|c|c|c|c|c|c|c|c|}
\hline \multirow[t]{2}{*}{ Authorlyear } & \multicolumn{10}{|c|}{ Sampling } & \multicolumn{4}{|c|}{ Measurement } & \multicolumn{4}{|c|}{$\begin{array}{l}\text { Statistical } \\
\text { analysis }\end{array}$} & \multicolumn{2}{|c|}{ Overall rating } \\
\hline & I & $2 a$ & $2 \mathbf{b}$ & $2 c$ & 3 & 4 & $5 \mathbf{a}$ & $5 b$ & $5 c$ & 6 & $\mathrm{Ia}$ & Ib & $2 a$ & $2 \mathrm{2b}$ & 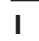 & 2 & 3 & 4 & & \\
\hline$\overline{\text { Brown et al }}{ }^{19}$ & 0 & 0 & I & 0 & 0 & I & $\mathrm{n} / \mathrm{a}$ & $\mathrm{n} / \mathrm{a}$ & 0 & I & 0 & 0 & I & I & $\mathrm{I}$ & 0 & 0 & 0 & $6 / 14(0.43)$ & Weak \\
\hline Salbach et $\mathrm{al}^{16}$ & I & 0 & I & 0 & 0 & I & $\mathrm{n} / \mathrm{a}$ & $\mathrm{n} / \mathrm{a}$ & 0 & I & 0 & 0 & I & I & I & I & $\mathrm{I}$ & 0 & $9 / 14(0.64)$ & Mod-weak \\
\hline Bridges et al ${ }^{17}$ & I & 2 & 0 & 0 & I & I & $\mathrm{n} / \mathrm{a}$ & $\mathrm{n} / \mathrm{a}$ & 0 & I & 0 & 0 & 0 & I & I & 1 & 0 & 0 & $9 / 14(0.64)$ & Mod-weak \\
\hline Nelson and Steele ${ }^{20}$ & 0 & 2 & 0 & 0 & 0 & I & $\mathrm{n} / \mathrm{a}$ & $\mathrm{n} / \mathrm{a}$ & 0 & I & 0 & 0 & 0 & 0 & 1 & 1 & 0 & 0 & $6 / 14(0.43)$ & Weak \\
\hline Byham-Gray et $\mathrm{al}^{2 ।}$ & I & 0 & I & 0 & I & I & $\mathrm{n} / \mathrm{a}$ & $\mathrm{n} / \mathrm{a}$ & 0 & I & 0 & 0 & I & I & l & 1 & 0 & 0 & $9 / 14(0.64)$ & Mod-weak \\
\hline Grimmer-Somers et $\mathrm{al}^{18}$ & I & 2 & 0 & 0 & I & I & $\mathrm{n} / \mathrm{a}$ & $\mathrm{n} / \mathrm{a}$ & 0 & I & 0 & 0 & 0 & 0 & I & 1 & I & 0 & $9 / 14(0.64)$ & Mod-weak \\
\hline
\end{tabular}

Notes: [ Sampling] I: probability sampling used; 2: individuals selected representative of the target population; 3: sample size justified; 4: Sample drawn from more than one site; 5: Matching groups; 6: Response rate > 50\%. [Measurement] I: Dependent variable (self-reported OR directly measured); $2:$ Dependent variable reliably and validly measured. [Statistical analysis] I: Statistical test appropriate; 2: P-values reported; 3: Confidence Intervals reported; 4: Missing data managed. 
Table 2 Summary of predictor variables examined and outcome measures

\begin{tabular}{|c|c|c|c|c|}
\hline Author & Setting & $\begin{array}{l}\text { Participant } \\
\text { characteristics }\end{array}$ & $\begin{array}{l}\text { Individual determinants } \\
\text { or predictors examined } \\
\text { (independent variable) }\end{array}$ & $\begin{array}{l}\text { Research evidence } \\
\text { use measures } \\
\text { (dependent variable) }\end{array}$ \\
\hline Brown et al ${ }^{19}$ & $\begin{array}{l}\text { Australia, UK } \\
\text { and Taiwan }\end{array}$ & $\begin{array}{l}\text { Occupational therapists } \\
\text { (OT) in either Australia, } \\
\text { UK or Taiwan, working } \\
\text { primarily with children } \\
\text { and/or adolescents } \\
\text { aged birth to } 18 \text { years }\end{array}$ & $\begin{array}{l}\text { - Demographic (Age) } \\
\text { - Education (OT qualification) } \\
\text { - Attitude (KAP survey score, } \\
\text { showing attitude towards establishing } \\
\text { best practice) } \\
\text { - Professional characteristics } \\
\text { (time in profession) }\end{array}$ & $\begin{array}{l}\text { EROS (Edmonton Research } \\
\text { Orientation Survey) subscales } \\
\text { and total score } \\
\text { (5 dependent variables) } \\
\text { - Valuing research } \\
\text { - Research involvement } \\
\text { - Being at the leading edge } \\
\text { - Evidence-based practice (EBP) } \\
\text { - Total score }\end{array}$ \\
\hline Salbach et $\mathrm{al}^{16}$ & Canada & $\begin{array}{l}\text { Physical Therapists in } \\
\text { clinical practice who } \\
\text { provided services to } \\
\text { adults with stroke }\end{array}$ & $\begin{array}{l}\text { - Demographics (age, gender) } \\
\text { - Education (degree earned) } \\
\text { - Attitudes (perceived usefulness } \\
\text { of research) } \\
\text { - Involvement in research or EBP-related } \\
\text { activities (Education about EBP) } \\
\text { - Professional characteristics } \\
\text { (work experience; membership in } \\
\text { professional organisation) }\end{array}$ & $\begin{array}{l}\text { Information-seeking behaviour } \\
\text { - Frequency of } \\
\text { searching online } \\
\text { bibliographic databases } \\
\text { - Frequency of reading the } \\
\text { research literature }\end{array}$ \\
\hline Bridges et al ${ }^{17}$ & USA (Georgia) & $\begin{array}{l}\text { Physical therapists } \\
\text { licensed to practice } \\
\text { in Georgia }\end{array}$ & $\begin{array}{l}\text { - Demographics (age) } \\
\text { - Education (highest degree held) } \\
\text { - Beliefs and attitude (practicality, } \\
\text { non-conformity) } \\
\text { - Professional characteristics } \\
\text { (years licensed as PT; percentage } \\
\text { of time spent in direct patient care) }\end{array}$ & $\begin{array}{l}\text { Propensity to adopt EBP } \\
\text { Evidence versus } \\
\text { experience scale }\end{array}$ \\
\hline $\begin{array}{l}\text { Nelson and } \\
\text { Steele }\end{array}$ & USA (Kansas) & $\begin{array}{l}\text { Master's or doctoral } \\
\text { level mental health } \\
\text { practitioners } \\
\text { (psychologists or } \\
\text { social workers) spending } \\
\text { at least } 25 \% \\
\text { of professional time in } \\
\text { clinical practice }\end{array}$ & $\begin{array}{l}\text { - Education (master's or } \\
\text { doctoral degree) } \\
\text { - Attitudes (practitioner's attitudes } \\
\text { using 'Positive attitudes toward } \\
\text { treatment research scale' and } \\
\text { 'Negative attitudes toward } \\
\text { treatment research scale') } \\
\text { - Involvement in research or EBP-related } \\
\text { activities (Participation in EBP class) } \\
\text { - Professional characteristics (years of clinical } \\
\text { experience) } \\
\text { - Clinical setting (private practice, } \\
\text { hospital setting, community health, } \\
\text { centre, school, university } \\
\text { clinic, others) }\end{array}$ & $\begin{array}{l}\text { Self-reported use of } \\
\text { evidence-based } \\
\text { practice } \\
\text { Measured by means of } \\
\text { self-reported response } \\
\text { to the question: } \\
\text { "How often } \\
\text { do you use } \\
\text { evidence-based } \\
\text { practice in } \\
\text { your clinical work?" }\end{array}$ \\
\hline $\begin{array}{l}\text { Byham-Gray } \\
\text { et al }{ }^{21}\end{array}$ & USA & $\begin{array}{l}\text { Registered dietitians } \\
\text { who belonged to one } \\
\text { of the dietetic practice } \\
\text { groups of American } \\
\text { Dietetic Association }\end{array}$ & $\begin{array}{l}\text { - Demographics (age and gender) } \\
\text { - Education (educational level) } \\
\text { - Involvement in research/EBP- } \\
\text { related activities (continuing education } \\
\text { or training specific to computer } \\
\text { technology, and research) } \\
\text { - Professional characteristics } \\
\text { (employment status, years of work } \\
\text { experience, membership in a } \\
\text { professional association) } \\
\text { - Employment setting (type of } \\
\text { institution and job classification) } \\
\text { - Information seeking (frequency of } \\
\text { professional reading, last time read research) }\end{array}$ & $\begin{array}{l}\text { Perceptions, attitudes, knowledge } \\
\text { of evidence-based practice } \\
\text { PAK score (perceptions, } \\
\text { attitudes, knowledge) }\end{array}$ \\
\hline
\end{tabular}


Table 2 (Continued)

\begin{tabular}{|c|c|c|c|c|}
\hline Author & Setting & $\begin{array}{l}\text { Participant } \\
\text { characteristics }\end{array}$ & $\begin{array}{l}\text { Individual determinants } \\
\text { or predictors examined } \\
\text { (independent variable) }\end{array}$ & $\begin{array}{l}\text { Research evidence } \\
\text { use measures } \\
\text { (dependent variable) }\end{array}$ \\
\hline $\begin{array}{l}\text { Grimmer- } \\
\text { Somers et al }\end{array}$ & Australia & $\begin{array}{l}\text { Registered } \\
\text { physiotherapists in } \\
\text { South Australia }\end{array}$ & $\begin{array}{l}\text { - Education (Bachelor Degree or } \\
\text { equivalent, honours degree or postgraduate } \\
\text { diploma, master's degree or PhD) } \\
\text { - Attitude (Attitude to undertaking } \\
\text { further research) } \\
\text { - Involvement in research (experience } \\
\text { of undertaking research) } \\
\text { - Professional characteristics (years of } \\
\text { practice; amount of time spent in } \\
\text { patient care) } \\
\text { - Work environment (private } \\
\text { practice/consultancy/locum, private/public } \\
\text { hospital, government department/university, } \\
\text { aged care facility/physical } \\
\text { development/disability/other) }\end{array}$ & $\begin{array}{l}\text { Perceived importance of research } \\
\text { Australian-relevant version } \\
\text { of National Health Service } \\
\text { survey instrument }\end{array}$ \\
\hline
\end{tabular}

have significant correlation with research uptake. Education and professional characteristics were the most commonly examined individual determinants, while information-seeking was the least commonly reported.

\section{Sociodemographic factors}

Four studies assessed one or more individual determinants in this category, ${ }^{16,17,19,21}$ and only two found significant relationships. ${ }^{16,17}$ Age was examined by four studies ${ }^{16,17,19,21}$ and gender was considered in two articles. ${ }^{16,21}$ In physiotherapy, being male was associated with the frequency of searching online databases. ${ }^{16}$ In another study involving physiotherapists, age was found to have a negative correlation with propensity to adopt EBP. ${ }^{17}$

\section{Education}

All six studies examined the relationship between educational background and different measures of research evidence use. ${ }^{16-21}$ Dietitians who were working on their doctoral degrees or those with advanced-level board certifications had significantly higher PAK (perceptions, attitudes, and knowledge of evidence-based practice) scores than their counterparts. $^{21}$ Three studies $^{16-18}$ examined the relationship between education and evidence uptake in physiotherapy but only two reported results. In one of the articles, holding a postgraduate degree was a significant predictor of positive perceived importance of research. ${ }^{18}$ In the other study involving physiotherapists, the higher the degree of education obtained, the more likely they were to demonstrate propensity to adopt EBP. ${ }^{17}$ Similarly for occupational therapists, higher levels of academic qualification were predictive of self-reported EBP uptake. ${ }^{19}$ However, for mental health practitioners such as social workers and psychologists, no difference was found between doctoral and masters' level of practitioners. ${ }^{20}$

\section{Beliefs and attitudes}

Five studies assessed one or more determinants in this category. ${ }^{16-20}$ Two studies ${ }^{18,20}$ assessed attitude towards research while one study ${ }^{19}$ examined attitudes toward establishing current best practice. Perceptions about organizational support and usefulness of research were reported in one study. ${ }^{16}$ Practicality, ${ }^{17}$ nonconformity ${ }^{17}$ and self-efficacy ${ }^{16}$ were measured in two studies. A positive correlation between perceptions, attitudes, beliefs, and evidence uptake was consistently found in all studies.

\section{Involvement in research or EBP-related activities}

Involvement in research or EBP-related activities was examined in four studies, all of which found significant associations with research evidence use. ${ }^{16,18,20,21}$ Allied health practitioners such as physiotherapists, ${ }^{16}$ social workers, ${ }^{20}$ psychologists, ${ }^{20}$ and dietitians ${ }^{21}$ who had previous research experience, participated in research activities at work or have taken a research or EBP course were likely to report use of EBP, engage themselves in information-seeking behavior, report positive perceptions and attitudes towards research, and consider it important.

\section{Professional characteristics/experiences}

All six studies assessed one or more individual determinants in this category and the most frequently examined factors 


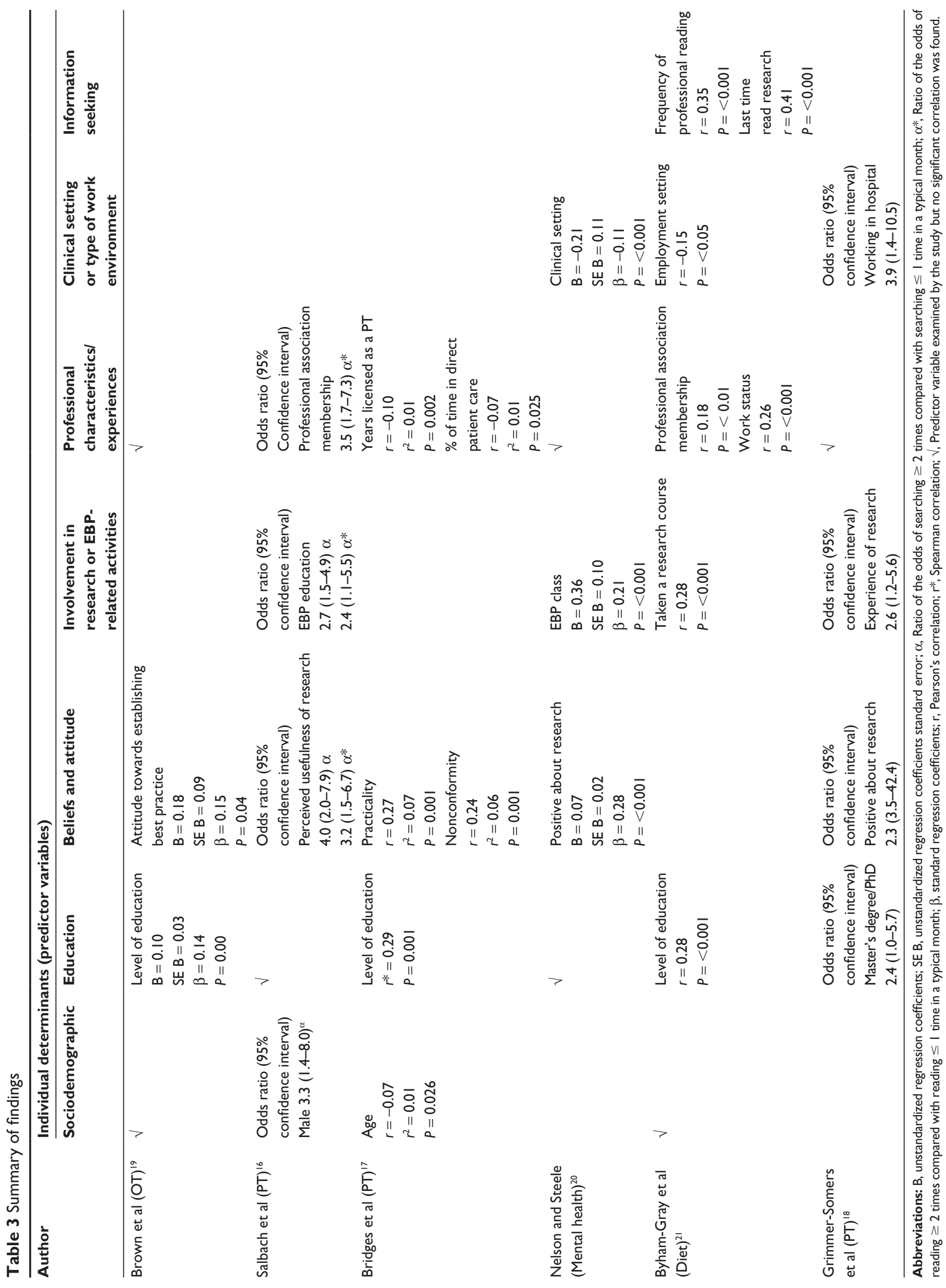


were years of practice, or work experience. ${ }^{16-21}$ However a significant relationship between work experience and evidence uptake was found in only one. ${ }^{17}$ This study found a negative correlation between the number of years licensed and propensity to adopt EBP in physiotherapists. Membership in a professional organization was associated with reading the research literature among physiotherapists. ${ }^{16}$ Dietitians who are members of at least two professional associations showed higher perception, attitude, and knowledge (PAK) scores compared to those whose membership is in only one association. ${ }^{21}$ This paper also reported that working full-time was also associated with higher PAK scores in dietitians. There was a negative correlation between percentage of time in direct patient care and propensity to adopt EBP in physiotherapy. ${ }^{17}$

\section{Clinical setting or type of work environment}

Only three studies reported findings in this category. ${ }^{18,20,21}$ Mental health workers from hospitals or university clinics reported higher levels of EBP use compared to those working in private practice, community mental health centre, schools, and other clinical settings. ${ }^{20}$ In physiotherapy, working in a hospital is a significant predictor of positive perceived importance of research. ${ }^{18}$ Registered dietitians employed by universities and colleges scored significantly higher PAK scores than other practice settings such as acute care, ambulatory care, long term care, private office, and community. ${ }^{21}$

\section{Information seeking}

Only one study examined the relationship between reading publications and research evidence use. ${ }^{21}$ Dietitians who read professional publications bimonthly, weekly, or daily have higher PAK scores than those who reported reading monthly. ${ }^{21}$

\section{Summary of results}

This review described a number of individual factors that were associated with the uptake of research evidence into AH clinical practice. Figure 2 illustrates the synthesized findings from the reviewed literature. The review demonstrated that factors such as educational degree or academic qualification, involvement in research or EBP-related activities, and practitioners' perceptions, attitudes and beliefs about research, and EBP are significant predictors of selfreported EBP use in $\mathrm{AH}$. The effect of other factors such as professional characteristics, clinical setting/work environment, information-seeking behavior, and sociodemographic variables (eg, age, gender) are less clear. Whether there is an interaction effect between evidence-uptake factors has not been tested.

\section{Discussion}

The diverse geographic origin of studies identified in this review highlights a worldwide interest in understanding why $\mathrm{AH}$ practitioners adopt evidence into clinical practice
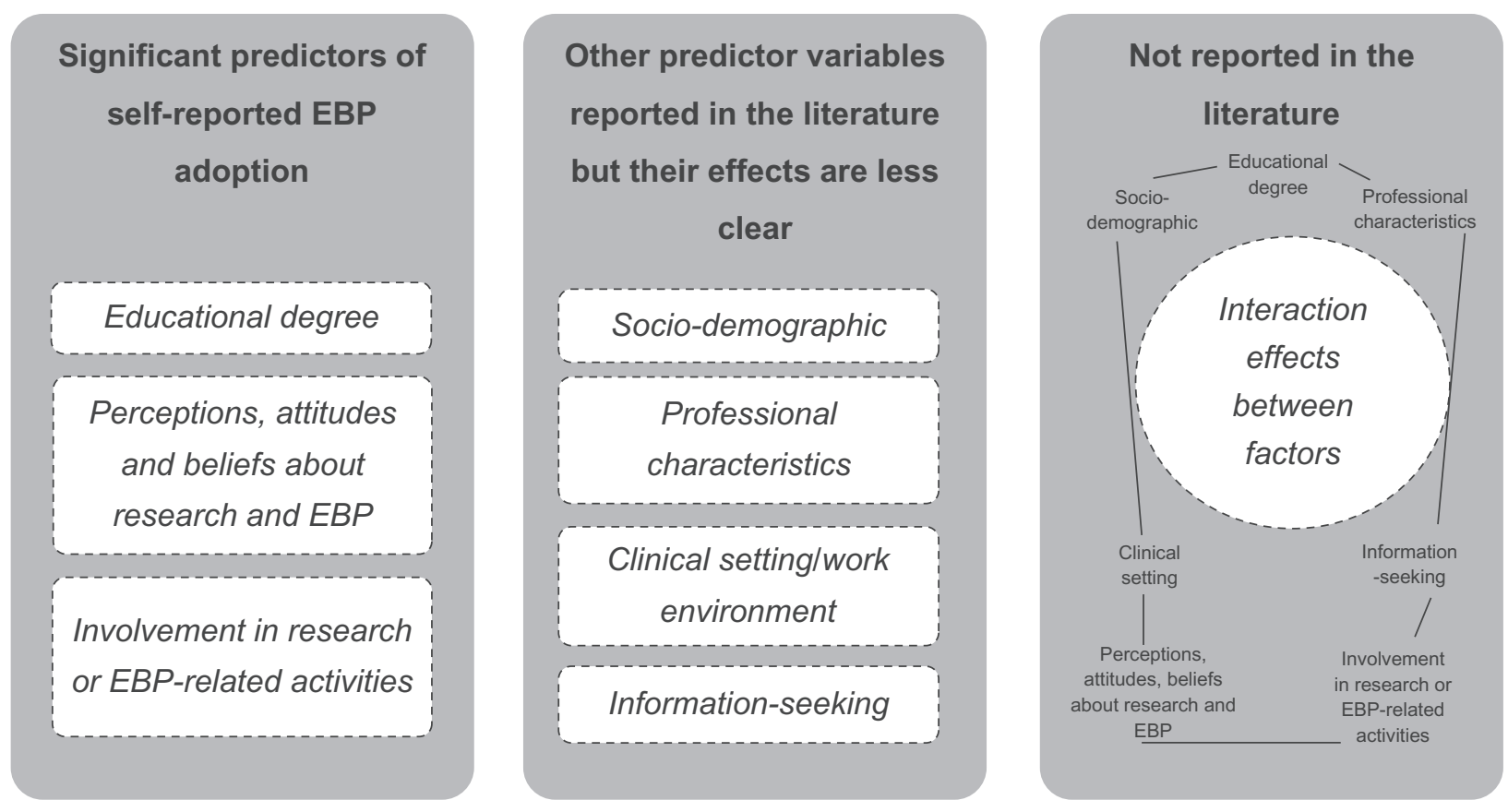

Figure 2 Summary of synthesized evidence on predictor variables. 
decisions. This validated the importance of bringing this information together in a review, so that efforts to address the research-practice gap can be addressed efficiently and effectively. The current review showed that factors such as educational degree or academic qualification, involvement in research or EBP-related activities, and practitioners' perceptions, attitudes and beliefs about research, and EBP are significant predictors of self-reported research evidence use in AH.

The educational or academic qualification of practitioners was a significant predictor of evidence uptake in AH. This finding concurs with other literature which reports an association between level of education and research utilization in nurses. ${ }^{15,22}$ It could be argued that the academic or educational level in itself may not be the important predictor in EBP but the research knowledge obtained during additional education. This contention concurs with our review finding that $\mathrm{AH}$ practitioners who had been involved in research or EBP-related activities (ie, participation in research activities, or have taken a course in research or EBP) are likely to report uptake of research evidence, and regard it as important. Similar outcomes have been reported in nursing literature, which show that clinicians who have previous exposure to research perceive EBP more favorably than those who have not been exposed. ${ }^{23-25}$ In medicine, McColl et $\mathrm{al}^{26}$ reported that physicians who were educated about research and participated in a practice-based research network had positive perceptions of EBP. It seems logical therefore, that if $\mathrm{AH}$ practitioners are to use research evidence in making decisions about the care of individual clients, they should be provided with training or education about research and EBP. To adopt an evidence-based approach, they should have the knowledge and skills to undertake the processes involved in EBP, which include formulating clinical questions, searching for relevant evidence, critically appraising evidence, implementing it into practice, and evaluating outcomes. ${ }^{27,28}$ Without these requisite knowledge and skills, $\mathrm{AH}$ practitioners may find it difficult to find, interpret, contextualize, and operationalize research evidence in practice. Previous studies, which have examined the impact of training programs to facilitate learning of EBP processes, have shown improvements in EBP competencies. ${ }^{29-34}$ The literature supports the importance of providing such training to health care practitioners to adopt an evidence-based approach. ${ }^{32-34}$ Our review results propose that exposure to research and EBP should be initiated in an undergraduate setting and then followed up in postgraduate training in order to produce optimum influence on research evidence uptake. Such an approach can instill a culture of research and harness EBP philosophy among health practitioners.

This review also found that perceptions, attitudes, and beliefs about EBP and research were significant predictors of research uptake in AH. Earlier studies found similar results for nurses, and reported a strong support for a link between beliefs and attitudes, and research utilization in nursing. ${ }^{15,35}$ Practitioners who perceive research as relevant to their work may be expected to be more open to EBP than those who view research as irrelevant to their practice. Those who have negative attitudes generally reflect a belief that EBP forces the practitioner to use research evidence as the sole basis for making clinical decisions, with little regard to clinical experience and patients' unique circumstances. ${ }^{36,37}$ One of the frequently cited barriers in EBP is negative attitude which reflects the misconception about the use of research evidence in clinical practice. ${ }^{37-39}$ Correcting this misconception about what EBP is, and what it is not, may facilitate EBP uptake. ${ }^{27,40,41}$ It is therefore important to emphasize that EBP does not consider research as the only source of evidence but rather suggests that research evidence be considered alongside clinical experience and patient values when making clinical decisions. The use of research evidence in practice would likely increase if $\mathrm{AH}$ practitioners have a better understanding of the EBP processes and what research evidence is.

Our review findings suggest that improving the research knowledge of practitioners and overcoming negative attitudes toward EBP have the potential to move AH practitioners towards regularly utilizing evidence in practice. According to Menon et al, ${ }^{42}$ "Knowledge acquisition creates a strong foundation for promoting change in clinicians' attitudes and practice behaviors, with the ultimate goal of improving patient-related outcome." Allied health practitioners who do not have substantial knowledge about research, and do not have positive attitudes towards EBP may benefit from strategies that facilitate collaborative work between practitioners and researchers. Studies suggest that collaboration between research and practice may play a key role in the process leading to evidence-based practice innovations. ${ }^{43-47}$ Partnership between researchers and $\mathrm{AH}$ practitioners may result in amalgamation of expertise that may enhance the process of utilizing research evidence into practice. Researchers can mentor practitioners on how to develop answerable clinical questions, formulate a search strategy, and critique research evidence. ${ }^{43}$ Practitioners, on the other hand, can help in developing research questions which are more in line with their needs, and hence could have a positive impact on the 
perceived value of research to practice. ${ }^{47,48}$ This collaborative approach may work effectively in clinically integrated interventions such as journal clubs or case discussions. There is emerging evidence from the literature that journal clubs which utilize a partnership between researchers/academics and practitioners may encourage EBP. ${ }^{49,50}$ Being involved in regular professional development activities such as journal clubs can put AH practitioners at the same levels of thinking and awareness of research evidence which are recognized to facilitate adoption of EBP. ${ }^{50-52}$

This review has limitations which should be considered when interpreting the results. First, this study examined only the individual determinants of research evidence use and did not address contextual and organizational factors (eg, culture, structure, resources) which have both been identified to influence evidence uptake by practitioners. ${ }^{38,53,54}$ This is important because focusing only on how individual $\mathrm{AH}$ practitioners use evidence is insufficient as practice occurs in organizational contexts. Future research should aim to review these other factors and explore the interaction between characteristics of individual practitioners and the contextual components in the organization. This will ensure a targeted and holistic approach for effective and sustainable change in AH practices. Second, it is evident from this review that there has been reliance on self-report as a measure of research evidence use in AH. Social desirability bias in self-reported outcomes is believed to lead to overestimation of performance which does not reflect actual practice. ${ }^{55,56}$ On average, clinicians tend to overestimate their adherence to recommended practices by a median absolute difference of $27 \% .{ }^{55}$ Consequently the objective measurement of evidence uptake remains a persistent and unresolved problem. Currently, one of the most serious limitations to furthering research on EBP in AH practice is the lack of sensitive and valid measures of clinical behavior. This should be the subject of future research in the field of EBP implementation.

\section{Conclusion}

This review suggests that the most important individual determinants of research evidence use in $\mathrm{AH}$ are "level of academic qualification," "being involved in research- or EBP-related activities" and "having positive perceptions, attitudes and beliefs about research or EBP."

\section{Implications to practice}

Our findings highlighted the importance of understanding the unique characteristics of individual $\mathrm{AH}$ practitioners when designing interventions to address the researchpractice gap. Efforts to promote evidence uptake in $\mathrm{AH}$ need to take into consideration these individual differences. Providing individually-targeted, multifaceted strategies is necessary to achieve change in the practice behavior of $\mathrm{AH}$ practitioners. Integral to these EBP strategies is an educational component. Therefore, opportunities should be made available to $\mathrm{AH}$ practitioners to engage in professional development activities relevant to EBP and research, such as journal clubs or case discussions. Pursuing postgraduate studies containing a significant research component can also influence AH practitioners' propensity to use research evidence.

\section{Implications to research}

Future research in the field of EBP implementation should focus on three important areas: exploring the interaction of the individual determinants of research evidence use and determining whether or not this can influence practitioner behavior; understanding the interface between practitioner characteristics and the contextual components of their organization in order to ensure sustainable change in practice; and designing an objective and psychometrically sound instrument to measure the uptake and sustainability of evidence-based clinical decision making.

\section{Disclosure}

The authors report no conflicts of interest in this work.

\section{References}

1. Sackett DL, Rosenberg WMC, Gray JAM, Haynes RB, Richardson WS. Evidence based medicine: what it is and what it isn't. BMJ. 1996; 312(7023):71-72.

2. Upton D, Upton P. Knowledge and use of evidence based practice by allied health and health science professionals in the United Kingdom. J Allied Health. 2006;35(3):127-133.

3. Metcalfe C, Lewin R, Wisher S, Perry S, Bannigan K, Moffett JK. Barriers to implementing the evidence base in four NHS therapies: dieticians, occupational therapists, physiotherapists, speech and language therapists. Physiotherapy. 2001;87(8):433-441.

4. Jette DU, Bacon K, Batty C, et al. Evidence-based practice: beliefs, attitudes, knowledge and behaviors of physical therapists. Phys Ther. 2003;83(9):786-805.

5. Bennett S, Tooth LR, McKenna KT, et al. Perceptions of evidence-based practice: a survey of Australian occupational therapists. Aust Occup Therap J. 2003;50(1):13-22.

6. Iles R, Davidson M. Evidence based practice: a survey of physiotherapists' current practice. Physiother Res Int. 2006;11(2):903-103.

7. Stevenson K, Lewis M, Hay E. Does physiotherapy management of low back pain change as a result of an evidence-based educational programme. J Eval Clin Pract. 2006;12(3):365-375.

8. Salls J, Dohli C, Silverman L, Hansen M. The use of evidence based practice by occupational therapists. Occup Ther Health Care. 2009;23(2):134-145. 
9. Rochette A, Korner-Bitensky N, Desrosiers J. Actual vs best practice for families post-stroke according to three rehabilitation disciplines. J Rehabil Med. 2007;39(7):513-519.

10. Gosling AS, Westbrook JI. Allied health professionals' use of online evidence: a survey of 290 staff working in the Australian public hospital system. Int J Med Inf. 2004;73(4):391-401.

11. Hadley J, Hassan I, Khan K. Knowledge and beliefs concerning evidence-based practice amongst complementary and alternative medicine health care practitioners and allied health care professionals: a questionnaire survey. BMC Complement Altern Med. 2008;8:45.

12. Taylor RS, Reeves BC, Ewings PE, Taylor RJ. Critical appraisal skills training for health care professionals: a randomized controlled trial. BMC Med Educ. 2004;4(1):30.

13. McCluskey A, Lovarini M. Providing education on evidence-based practice improved knowledge but did not change behaviour: a before and after study. BMC Med Educ. 2005;5:40.

14. Turnbull C, Grimmer-Somers K, Kumar S, May E, Law D, Ashworth E. Allied, scientific and complementary health professionals: a new model for Australian allied health. Aust Health Rev. 2009;33(1):27-37.

15. Squires JE, Estabrooks CA, Gustavsson P, Wallin L. Individual determinants of research utilisation by nurses: a systematic review update. Implementation Sci. 2011;6:1.

16. Salbach SM, Guilcher SJT, Jaglal SB, Davis DA. Factors influencing information seeking by physical therapists providing stroke management. Phys Ther. 2009;89(10):1039-1050.

17. Bridges PH, Bierema LL, Valentine T. The propensity to adopt evidencebased practice among physical therapists BMC Health Serv Res. 2007;7:103.

18. Grimmer-Somers K, Lekkas P, Nyland L, Young A, Kumar S. Perspectives on research evidence and clinical practice: a survey of Australian physiotherapists. Physiother Res Int. 2007;12(3):147-161.

19. Brown T, Tseng MH, Casey J, McDonald R, Lyons C. Predictors of research utilization among paediatric occupational therapists. OTJR Occup Part Heal. 2010;30(4):172-183.

20. Nelson TD, Steele RG. Predictors of practitioners self-reported use of evidence-based practices: practitioners training, clinical setting and attitudes towards research. Adm Policy Ment Health. 2007;34(4):319-330.

21. Byham-Gray LD, Gillbride JA, Dixon B, King Stage F. Evidence-based practice: what are dieticians' perceptions, attitudes and knowledge. J Am Diet Assoc. 2005;105(10):1574-1581.

22. Michel Y, Sneed N. Dissemination and use of research findings in nursing practice. J Prof Nurs. 1995;11(5):306-311.

23. Olade RA. Evidence-based practice and research utilization activities among rural nurses. J Nurs Scholarsh. 2004;36(3):220-225.

24. McCleary L, Brown GT. Association between nurses' education about research and their research use. Nurs Educ Today. 2003;23(8):556-565.

25. Tsai SL. Nurses' participation and utilization of research in the republic of China. Int J Nurs Stud. 2000;37(5):435-444.

26. McColl A, Smith H, White P, Field J. General practitioners' perceptions of the route to evidence-based medicine: a questionnaire survey $B M J$. 1998;316(7128):361-365.

27. Cordell WH, Chisholm CD. Will the real evidence please stand up? EMN 2001;23(6):11-14.

28. Dawes M, Summerskill W, Glasziou P, et al. Sicily statement on evidence-based practice. BMC Med Educ. 2005;5(1):1.

29. Richardson WS, Wilson MC, Nishikawa J, Hayward RS. The wellbuilt clinical question: a key to evidence-based decisions. ACP JClub. 1995;123(3):12-13.

30. Rosenberg WM, Deeks J, Lusher A, Snowball R, Dooley G, Sackett D. Improving searching skills and evidence retrieval. JR Coll Physicians Lond. 1998;32(6):557-563.

31. Taylor R, Reeves B, Ewings P, Binns S, Keast J, Mears R. A systematic review of the effectiveness of critical appraisal skills training for clinicians. Med Educ. 2000;34(2):120-125.
32. Parkes J, Hyde C, Deeks JJ, Milne R. Teaching critical appraisal skills in health care settings. Cochrane Database Syst Rev. 2001;3: CD001270.

33. Flores-Mateo G, Argimon JM. Evidence based practice in postgraduate healthcare education: a systematic review. BMC Health Serv Res. 2007; 7:119.

34. Ilic D. Teaching evidence-based practice: perspectives from the undergraduate and postgraduate viewpoint. Ann Acad Med Singapore. 2009;38(6):559-565.

35. Eller LS, Kleber E, Lanwang S. Research knowledge, attitudes and practices of health professionals. Nurs Outlook. 2003;51(4):165-170.

36. DiCenso A, Cullum N, Ciliska D. Implementing evidence-based nursing: some misconceptions. Evid Based Nurs. 1998;1:38-39.

37. Pagoto SL, Spring B, Coups EJ, Mulvaney S, Coutu MF, Ozakinci. Barriers and facilitators of evidence-based practice perceived by behavioral science health professionals. J Clin Psychol. 2007;63(7): 695-705.

38. Grol R, Wensing M. What drives change? Barriers to and incentives for achieving evidence-based practice. Med J Aust. 2004;180(Suppl 6): S57-S60.

39. Belizan M, Meier A, Althabe F, et al. Facilitators and barriers to adoption of evidence-based practice perinatal care in Latin American hospitals: a qualitative study. Health Educ Res. 2007;22(6): 839-853.

40. Jennings BM, Loan LA. Misconceptions amongst nurses about evidence-based practice. J Nurs Scholarsh. 2001;33(2):121-127.

41. Turkelson C, Hughes JE. Why aren't you doing evidence-based practice? AAOS Bulletin. 2006;54(3):1-4.

42. Menon A, Korner-Bitensky N, Kastner M, McKibbon KA, Straus S. Strategies for rehabilitation professionals to move evidence-based knowledge into practice: a systematic review. J Rehabil Med. 2009; 41(3):1024-1032.

43. Rosswurm MA, Larrabee JH. A model for change to evidence-based practice. Image J Nurs Sch. 1999;31(4):317-322.

44. Landry R, Amara N, Lamari M. Utilization of social science knowledge in Canada. Res Policy. 2001;30(2):333-349.

45. Fox NJ. Practice-based evidence: towards collaborative and transgressive research. Sociology. 2003;37(1):81-102.

46. Osterling KL, Austin MJ. The dissemination and utilization of research for promoting evidence-based practice. J Evid Based Soc Work. 2008;5(1-2):295-319.

47. Chagnon F, Pouliot L, Gervais MJ, Pigeon ME. Comparison of determinants of research utilization by practitioners and administrators in the field of child and family social services. Implement Sci. 2010;5:41.

48. Berger R. Practitioners in search of evidence. J Soc Work. 2010;10(2): 175-191.

49. Austin TM, Richter RR, Frese T. Using a partnership between academic faculty and a physical therapist to develop a framework for an evidence-based journal club: a discussion. Physiother Res Int. 2009;14(4):213-223.

50. Lizarondo L, Kumar S, Grimmer-Somers K. Supporting allied health practitioners in evidence-based practice: a case report. Int JTher Rehabil. 2009;16(4):226-236.

51. McQueen J, Miller C, Nivison C, Husband V. An investigation into the use of journal club for evidence-based practice. Int J Ther Rehab. 2006;13(7):311-316.

52. Campbell-Fleming J, Catania K, Courtney L. Promoting evidencebased practice through a travelling journal club. Clin Nurse Spec. 2009;23(1):16-20.

53. Bostrom AM, Wallin L, Nordstrom G. Evidence-based practice and determinants of research use in elderly care in Sweden. J Eval Clin Pract. 2007;13(4):665-673.

54. Salbach NM, Jaglal SB, Jorner-Bitensky N, Rappolt S, Davis D. Practitioner and organizational barriers to evidence-based practice of physical therapists for people with stroke. Phys Ther. 2007;87(10): 1284-1303. 
55. Adams AS, Soumerai SB, Lomas J, Ross-Degnan D. Evidence of selfreport bias in assessing adherence to guidelines. Int $J$ Qual Health Care. 1999;11(3):187-192.
56. Van de Mortel TF. Faking it: social desirability response bias in selfreport research. Aust J Adv Nurs. 2008;25(4):40-48.

\section{Publish your work in this journal}

The Journal of Multidisciplinary Healthcare is an international, peerreviewed open-access journal that aims to represent and publish research in healthcare areas delivered by practitioners of different disciplines. This includes studies and reviews conducted by multidisciplinary teams as well as research which evaluates the results or conduct of such teams or healthcare processes in general. The journal covers a wide range of areas and welcomes submission from practitioners at all levels, from all over the world. The manuscript management system is completely online and includes a very quick and fair peer-review system. Visit http://www.dovepress.com/testimonials.php to read real quotes from published authors.

Submit your manuscript here: http://www.dovepress.com/journal-of-multidisciplinary-healthcare-journal 